\title{
O convívio concomitante e frugal das escolas elementares públicas e privadas paulistanas
}

\section{The concurrent and frugal living of public and private elementary schools from the city of São Paulo}

\author{
Eliane Mimesse Prado ${ }^{1}$
}

\begin{abstract}
RESUMO
Este artigo analisa as escolas elementares existentes na cidade de São Paulo nos anos iniciais do século XX. Serão analisadas apenas as escolas públicas isoladas e as privadas elementares subsidiadas pelo governo italiano. O período escolhido justifica-se pelo alto número de escolas subsidiadas em funcionamento na cidade. Objetiva-se entender como os governos paulista e italiano geriram essas escolas na cidade. As fontes utilizadas para esta pesquisa foram o periódico Fanfulla; os relatórios de diretores e inspetores do ensino, existentes nos Annuarios do Ensino do Estado de São Paulo, alocados no acervo do Arquivo Público do Estado de São Paulo; e o Annuario delle scuole italiane all'estero governative e sussidiate, que se encontra no acervo da Biblioteca Nazionale Centrale di Roma. A fundamentação baseou-se, entre outros autores, em Pereira (2010), que trouxe o contexto da cidade paulistana no período estudado; Souza (2009), por focar a escolarização primária; Salvetti (2014), que descreveu a constituição da associação "Dante Alighieri". Considera-se que as escolas subsistiram concomitantemente com objetivos similares, mas o governo paulistano conseguiu suprir, paulatinamente, em parte, a defasagem das vagas, solapando as escolas subsidiadas.

Palavras-chave: escolarização elementar; imigrantes peninsulares; história da educação.
\end{abstract}

DOI: $10.1590 / 0104-4060.40994$

1 Centro Universitário Internacional. Programa de Pós-Graduação em Educação e Novas Tecnologias. Curitiba, Paraná, Brasil. Rua 13 de Maio, nº 538. CEP: 80510-030. E-mail: emimesse@bol.com.br 


\begin{abstract}
This article studies elementary schools from the city of São Paulo in the early $20^{\text {th }}$ century. Only isolated public schools and elementary private ones that were subsidized by the Italian government will be studied. The choice for that period of time was motivated by the high number of active subsidized schools in the city. Our aim is to understand how the governments from the city of São Paulo and from Italy managed those schools in the city. The sources used for this research were the Fanfulla newspaper; the reports from principals and school inspectors existing in the Annuarios do Ensino do Estado de São Paulo, which are located in the collection of Public Archives from the State of São Paulo; and the Annuario delle scuole italiane all'estero governative e sussidiate which can be found in the collection of the Biblioteca Nazionale Centrale di Roma. The theoretical foundation was based on authors such as Pereira (2010) who brought the context of the city of São Paulo in the period studied; Souza (2009) for focusing on primary schooling; Salvetti (2014) who described the establishment of the "Dante Alighieri" association. Our conclusion shows that the schools existed concurrently with similar goals, but the government from the city of São Paulo was able to gradually make up the lack of school vacancies by undermining the subsidized schools.
\end{abstract}

Keywords: elementary schooling; peninsular immigrants; history of education.

\title{
Introdução
}

A cidade de São Paulo recebeu um grande número de estrangeiros que chegaram à Hospedaria dos Imigrantes nos anos finais do século XIX e iniciais do XX. Essa situação gerou preocupação no governo estadual, especialmente em se tratando da escolarização dos filhos desses imigrantes, como foi constatado na análise dos Annuarios do Ensino do Estado de São Paulo. Os imigrantes, por sua vez, também estavam interessados na aprendizagem das crianças, como pode ser comprovado pelas inúmeras escolas elementares privadas criadas na capital. As referidas scuole elementari eram similares em sua organização às escolas isoladas públicas, existentes na cidade.

De acordo com Pereira (2010), somente na cidade paulistana a população era por volta de 28 mil habitantes no ano de 1874, passou para cerca de 240 mil em 1900 e atingiu o total de 477.992 em 1914. Com a expansão e a importância na produção e exportação de café, a cidade se tornou um polo de convergência dos interesses dos mais diversos. Com o crescimento descomedido da população 
urbana, foi necessário que os próprios estrangeiros se organizassem, na tentativa de suprirem as lacunas que o governo local não conseguia preencher. $\mathrm{O}$ amplo número de peninsulares residentes na cidade proporcionou ao governo italiano desenvolver ações no sentido de difundir a língua e a cultura de seu país. Esse governo enviava subsídios para as colônias estabelecidas fora da península itálica, visando à criação e manutenção de escolas elementares. Justificando-se a criação e o funcionamento dessas escolas na cidade, além de suprirem - em parte - a defasagem de vagas existentes nas escolas públicas.

\section{As escolas na cidade paulistana}

A cidade de São Paulo, de acordo com Biondi (2010, p. 24), se inseriu em um contexto singular, transformou-se, “[...] durante o século XX, na metrópole com o maior número de descendentes de italianos no mundo, caracterizando-se, no início de sua expansão, como a cidade industrial do Brasil, na qual a componente italiana era majoritária em todos os setores de trabalho". (BIONDI, 2010 , p. 24). Consequentemente ocorria o aumento da população em idade escolar na cidade, as escolas públicas dos anos iniciais, existentes na capital, não conseguiam suprir a demanda por vagas. Reafirmando essa premissa o Diretor Geral do Ensino, Oscar Thompson, escreveu em relatório de 1908.

O problema do ensino primario em São Paulo, reside na deficiencia de escolas publicas para comportar a população em edade escolar.

Ao governo faltam os recursos pecuniários para augmentar o numero de estabelecimentos de ensino, apezar da verba avultada que sob a rubrica - Instrucção Publica - absorve quantia não pequena da receita do Estado. (SÃO PAULO, 1908, p. 315).

O Inspetor Geral do Ensino João Lourenço Rodrigues, em relatório de $31 / 03 / 1908$, teceu considerações sobre as escolas italianas elementares fixadas na Capital e como contribuíam para a redução dos gastos do Estado.

Considerando apenas as escolas italianas da Capital, temos um effectivo de quase 5.000 crianças matriculadas. 
Si o governo tivesse de fornecer ensino gratuito a todos esses alunos, deveria crear mais de cem escolas, que acarretariam para o Estado uma despesa anual superior a trezentos contos.

Ora, desde que o ensino nestes estabelecimentos seja convenientemente regularizado, eles podem prestar bons e reaes serviços, e não é natural que taes serviços fiquem sem uma compensação, visto que proporcionam ao Estado uma economia tão avultada. (SÃO PAULO, 1907, p. 45).

Conforme os dados estatísticos do Annuario do Ensino do Estado de São Paulo (SÃO PAULO, 1907, p. 26), existiam na capital "17 Grupos Escolares com matrículas de 7.111 alunos". As escolas isoladas da cidade no ano de 1906 totalizaram 129, sendo 43 masculinas, 52 femininas e 34 mistas, essas escolas somavam 4.332 alunos matriculados. Levando-se em conta essa população escolar com mais de 11 mil alunos matriculados somente na capital, as escolas elementares italianas, com seus 5 mil alunos matriculados, foram providenciais apenas para suprir a demanda por vagas nesses anos iniciais do século XX. Qualquer ação do governo paulista - como a obrigatoriedade do ensino - seria adequadamente implementada "[...] quando tivermos escolas em numero sufficiente para comportar todos os candidatos á matricula". O Inspetor Geral do Ensino João Lourenço Rodrigues defendia a obrigatoriedade do ensino, somente após a reestruturação das vagas escolares, como consta do Annuario do Ensino do Estado de São Paulo. (SÃO PAULO, 1907, p. 40).

O trecho abaixo, escrito pelo Diretor Geral do Ensino Oscar Thompson, enfatizava a vontade dos pais de que seus filhos aprendessem a língua pátria, além de citar a defasagem de vagas nos grupos escolares.

São em grande numero as escolas extrangeiras, principalmente italianas, que funccionam no Estado. A colonia italiana domiciliada em São Paulo procura geralmente essas escolas, não sómente porque os nossos grupos escolares, principalmente na Capital, são insufficientes para as necessidades da população escolar, como sobretudo, porque os paes têm o natural e legitimo desejo de que seus filhos aprendam e cultivem a sua língua patria. (SÃO PAULO, 1909, p. 121).

As escolas públicas voltadas para os anos iniciais na cidade paulistana nos anos finais do século XIX e iniciais do século XX eram compostas por escolas isoladas de três tipos: femininas, masculinas e mistas, que continham uma única sala de aula, agregavam alunos de idades e níveis de aprendizagens diferentes; 
escolas reunidas, que uniam algumas escolas isoladas em um mesmo espaço físico e grupos escolares, que contavam com um professor específico para cada sala, essas eram organizadas segundo a idade e o nível de aprendizagem dos alunos.

Segundo descrição do Inspetor Geral do Ensino, João Lourenço Rodrigues, as escolas isoladas:

[...] com poucas excepções, estão mal installadas: salas acanhadas, sem conforto, sem hygiene e muitas dellas mesmo sem área para recreação dos alumnos. [...] Causa não menos perturbadora é a deficiencia e irregularidade da dotação. Na maior parte das escolas, mobiliário, material de ensino, livros, etc, tudo está consideravelmente estragado pelo uso e a pedir prompta e radical substituição. [...] A escola isolada tem um só professor, uma só classe, mas esta é composta de elementos heterogeneos relativamente á edade e ao desenvolvimento. (SÃO PAULO, 1907, p. 29).

Nesses anos estudados, as escolas isoladas eram normalmente citadas pelo então diretor geral do ensino e pelos inspetores escolares da capital e do interior, em seus relatórios contidos nos Annuarios do Ensino do Estado de São Paulo. As escolas isoladas eram localizadas um pouco mais distantes da área central da cidade e apresentavam deficiências no seu funcionamento. Eram listados os problemas quanto ao seu espaço físico, aos materiais didáticos, à formação dos professores e à diversidade de métodos de ensino aplicados.

A precariedade dessa modalidade escolar era ampla, a tal ponto que os relatos dos inspetores contidos nos Annuarios do Ensino do Estado de São Paulo tornaram-se a cada dia mais técnicos, na tentativa de ordenarem os trabalhos educativos desta modalidade escolar.

A conciliação das funções de vigilância e controle do trabalho docente esboça-se lentamente e acresce-se no final do século $X I X$ de argumentos que defendem cada vez com maior intensidade o exercício da orientação pedagógica pelos inspetores com vistas ao aperfeiçoamento da atuação dos professores. Assim, na própria produção dos Anuários, os relatórios dos inspetores escolares vão assumindo um tom técnico pelo qual se apresenta um diagnóstico da situação das escolas e da ação pedagógica dos professores de maneira a sistematizar as propostas de intervenção que são feitas. [...] Entre as dimensões técnica e do controle, os inspetores vão de modo progressivo instituindo saberes que submetem o trabalho docente 
a processos de ordenação e racionalização expressos em prescrições e aconselhamentos. (CATANI; LIMA, 2002, p. 158).

Normalmente, o espaço físico destinado a essas escolas era indevido, por ocupar um cômodo qualquer ou uma das salas de uma residência de família, neste caso, a família do professor. Outra questão era quanto à inexistência de um mobiliário escolar adequado, usavam-se bancos, caixotes de madeira, mesas improvisadas e cadeiras dos mais diversos tipos, muitas vezes cedidos pelos pais dos alunos. Ainda, ocorriam problemas com a distribuição dos materiais escolares, requisitados pelo professor no início do ano letivo. Esses materiais nem sempre chegavam até as escolas e, muitas vezes, eram enviados materiais equivocados. A remessa de livros e cadernos contemplava o que existia nos depósitos da Secretaria do Interior, na maioria das vezes os materiais escolares distribuídos não eram exatamente os mesmos solicitados, de acordo com Mimesse (2010).

Outra modalidade escolar eram as escolas reunidas. Na capital, até o ano de 1907 existiam três escolas reunidas, localizadas nos bairros do Bom Retiro, do Belenzinho e uma na Avenida Paulista. Conforme esclarecimento do Inspetor Geral do Ensino, João Lourenço Rodrigues, explicando sobre as escolas reunidas da cidade: "[...] a organização foi vazada nos moldes da organização dos grupos e todas ellas têm um diretor, aliás em comissão. Assim organisadas, as escolas reunidas são grupos em miniatura, tendo classes homogêneas e ensino graduado por anos", como consta no Annuario do Ensino do Estado de São Paulo. (SÃO PAULO, 1908, p. 36). As escolas reunidas eram consideradas mais adequadas ao ensino do que as escolas isoladas, por espelharem-se na organização dos grupos.

A discussão sobre a precariedade das escolas públicas isoladas e as censuras por elas acarretadas remontava à época imperial. Permaneciam, nesse sentido, os padrões escolares do Império durante os anos do regime republicano. Apesar dos debates sobre os assuntos educacionais ocorridos no final do período imperial, poucas foram as alterações concretas diante da precariedade do sistema escolar existente. Na prática, a organização dos estabelecimentos de ensino públicos continuava precária e conturbada, mesmo no início do novo século. Foi necessário um prenúncio com o aumento desmesurado da população em idade escolar na cidade, para que novas medidas fossem debatidas e, paulatinamente, institucionalizadas.

O governo do Estado de São Paulo, segundo os escritos do Diretor Geral da Instrução Pública Oscar Thompson, tinha a pretensão de unir as Escolas Isoladas em um mesmo espaço físico, passando a denominá-las de escolas reunidas, para após a efetivação desta reorganização alçá-las à categoria dos grupos escolares. 
Não sendo possível abolir completamente este typo de escola, elle vae sendo supprimido aos poucos, pelos grandes inconvenientes que apresentar, nas cidades e villas, conservando-se apenas nos bairros e districtos de paz mais afastados dos centros populosos. Onde haja um núcleo de escolas isoladas são ellas reunidas com feição de grupos escolares em miniatura e confiadas á direcção de um professor. (SÃO PAULO, 1909, p. 25).

Os diretores e inspetores escolares utilizavam em seus discursos, como parâmetro de comparação, os grupos escolares da capital e de algumas cidades do interior do estado de São Paulo. Os Grupos eram elogiados por apresentarem uma divisão clara nos horários, os professores tinham apenas uma turma e todos com o mesmo grau de adiantamento, além de receberem utensílios necessários ao ensino de todos os aprendizes, contavam ainda com a figura de um Diretor, que zelava pela magnitude do estabelecimento.

Os três tipos de escolas públicas voltadas para os anos iniciais na cidade formavam os alunos no curso primário, com duração de três anos nas escolas isoladas e de quatro anos nas reunidas e grupos escolares. O relatório do Inspetor Geral do Ensino João Lourenço Rodrigues esclarece a distribuição do trabalho nos grupos.

São os grupos escolares instituições de ensino preliminar destinadas a educar e instruir, consoante o regimen educativo moderno, posto em pratica na Escola-modelo, creanças de um e outro sexo.

O ensino é distribuido ordinariamente por quatro classes, correspondentes a cada um dos annos em que se divide o curso.

São leccionadas em cada classe todas as materias do programma [...] estabelecendo-se uma ordem gradual e crescente no ensino.

É exactamente na sequencia natural e logica que ha de um para outro anno, e no regimen da divisão do trabalho, com efficaz aproveitamento, das aptidões especiaes de cada professor, que repousa fundamentalmente a superioridade deste apparelho escolar. (SÃO PAULO, 1907, p. 134).

Essa opinião sobre os grupos escolares era defendida pelos diretores gerais do ensino e pelos inspetores escolares no período estudado. Souza (1998), explanando sobre os grupos escolares no estado de São Paulo, esclareceu que essa modalidade de escola específica para os anos iniciais de aprendizagem foi criada no estado nos anos 1890 e representou: 
[...] uma das mais importantes inovações no ensino. Tratava-se de uma organização administrativa e pedagógica mais complexa concebida nos princípios da racionalidade científica e na divisão do trabalho. Assim, a racionalidade pedagógica fundamentava-se na classificação dos alunos, no estabelecimento de um plano de estudos e na determinação da jornada escolar, resultando em um ensino mais homogêneo, padronizado e uniforme. (SOUZA, 1998, p. 16).

Apesar da existência de escolas públicas como os grupos escolares, as escolas reunidas e as escolas isoladas, ainda existiam na cidade as escolas elementares subsidiadas italianas. Todas essas modalidades de escolas abordavam o mesmo nível de ensino, os anos iniciais de aprendizagem. As escolas elementares subsidiadas poderiam ser criadas por qualquer peninsular, desde que esse benfeitor apoiasse a causa da instrução. Segundo as deliberações do Congresso delle Società ed Altre Istituzioni Italiane nel Brasile, registrado na publicação do periódico Fanfulla (1906, p. 822, tradução nossa), a iniciativa de criação de uma escola poderia ser por obra de um “[...] benemérito da instrução italiana e da sua difusão nesta terra surja a Escola italiana na qual será possivelmente anexa a um Colégio Interno, que será complementar ao aperfeiçoamento dos alunos”.

A abertura de escolas elementares subsidiadas pelos próprios peninsulares, seguindo o modelo das escolas existentes no território italiano, foi bem aceita pela comunidade residente na capital paulista. Essas escolas visavam à alfabetização das crianças estrangeiras e filhas de estrangeiros em língua italiana. Conforme Salvetti (2014, p. 60), as escolas subsidiadas deveriam seguir as circulares ministeriais, que prescreviam a necessidade de serem tolerantes e aceitarem "[...] o pluralismo: mesmo dando a preferência a estudantes italianos, poderiam ser admitidos alunos de qualquer nacionalidade e religião". (SALVETTI, 2014, p. 60).

Como foi descrito por Salvetti (2002, p. 48) a função das escolas italianas no exterior era a de enaltecer a educação nacional e o sentimento pátrio, utilizando-se "[...] da língua italiana como meio de manter forte o legado entre os emigrados e a mãe pátria”. (SALVETTI, 2002, p. 48, tradução nossa). A partir dos comentários do periódico Fanfulla (1906), pode-se verificar que as escolas subsidiadas italianas eram semelhantes às escolas isoladas. Apresentavam a mesma disposição, utilizavam uma única sala para todos os alunos do mesmo sexo, com níveis de aprendizagens e idades diferentes.

Os estrangeiros, principalmente os com formação acadêmica de origem peninsular, identificaram nesse momento a possibilidade de abrirem escolas elementares na cidade paulistana e ainda receberem subsídios do governo do 
seu país. Esses subsídios em espécie, segundo Salvetti (2014), foram quadruplicados nos anos de 1905-1906, quando a "Comissão Parlamentar de Vigilância reconheceu a necessidade de se privilegiar as escolas italianas nas Américas, na América Latina em primeiro lugar”. (SALVETTI, 2014, p. 68). Sendo essa uma hipótese para a ampliação do número de escolas criadas por professores leigos na capital paulista.

Normalmente, os professores eram também diretores e proprietários das escolas. Por sua vez, o governo italiano pretendia contribuir com a instrução da criança italiana, ou filha de italianos, que vivia fora da Itália desde a sedimentação do processo de unificação, que uniu as diferentes regiões, antes divididas em ducados, reinos, um grão-ducado e um estado pontifício. Essas regiões foram unificadas sob a égide de um novo estado, mas o idioma eleito como o oficial foi consequentemente imposto, gerando um grande número de habitantes que eram considerados, naquele momento - pelo governo - como analfabetos. Sendo assim, esta era mais uma hipótese que justificaria o crescente número de escolas subsidiadas paulistanas.

De acordo com os mapas estatísticos do Annuario do Ensino do Estado de São Paulo do ano de 1908, existiam nos bairros da cidade de São Paulo 77 escolas subsidiadas pelo governo italiano. Mas, no Annuario delle scuole italiane all'estero governative e sussidiate constavam 55 escolas subsidiadas, no mesmo ano de 1908. Algumas hipóteses podem ser descritas para justificar essa diferença no número de escolas listadas nos dois anuários. O número de 77 escolas que apareceu no anuário paulista deveria ser o mais recente, afinal os inspetores escolares conheciam e visitavam as escolas da capital durante todo o ano; em contraponto, não se sabe até o momento com qual frequência os dados das escolas italianas paulistanas eram enviados ao Ministério dos Assuntos Exteriores na Itália, justificando, deste modo, o número menor de escolas na listagem italiana.

$\mathrm{Na}$ cidade de São Paulo as escolas subsidiadas foram criadas nos bairros operários, com predomínio de peninsulares. O que ocorreu na cidade, após o estabelecimento dos imigrantes, foram representações de situações similares as que já existiam nas localidades de origem. As escolas elementares italianas, conforme os dados constantes nos Annuarios do Ensino do Estado de São Paulo, dos anos de 1907 a 1910, contavam, em média, com 6.537 alunos matriculados na capital.

É interessante verificar a localização das escolas, nos arredores da região central, em bairros como o Bom Retiro, Brás e Vila Mariana que, de acordo com Pereira (2010, p. 21), "[...] foram surgindo no entorno de áreas alagadas e insalubres próximas às fábricas" e, algumas vezes, eram cercados pelas linhas férreas. Outros bairros também fizeram parte deste grupo como Pari, Barra 
Funda, Bexiga e Cambuci. A população peninsular predominante nos bairros da cidade, segundo Trento (2002), era, no Bexiga, os provenientes da Calábria, no Bom Retiro, os do Vêneto, e no Brás, os da Campânia. Mas, para além desses bairros, existiam escolas italianas na região da Consolação, da rua de Santa Efigênia, da rua São Caetano, na Vila Buarque e na Ponte Grande, segundo os mapas estatísticos contidos no Annuario do Ensino do Estado de São Paulo de 1907. Deste modo, as escolas italianas estavam localizadas em bairros em que existiam grupos escolares e, provavelmente, também deveriam existir escolas isoladas.

As escolas elementares subsidiadas assumiram o dever de ensinar a língua e a cultura de seu país aos emigrados. De acordo com Cenni (2003, p. 323), era necessário alfabetizar os peninsulares na língua italiana, do país recém-unificado, antes que eles se alfabetizassem na língua portuguesa. O Congresso delle Società ed Altre Istituzioni Italiane nel Brasile debateu sobre a obrigação de se alfabetizarem crianças e adultos nos dois idiomas. Foi criada uma Comissão que propôs algumas considerações, como o reconhecimento aos que "[...] com sentimento de italianidade, patriotismo, amor e abnegação dedicaram-se e dedicam-se aos cuidados com a instrução e a educação". (FANFULLA, 1906, p. 822, tradução nossa).

A Comissão sugeriu pontos que deveriam ser votados, entre eles: “[...] que cada escola, junto ao aluno com certo grau de desenvolvimento e cultura intelectual, venha conceder-lhe o ensino da língua portuguesa, e com maior formação que hoje temos, as noções de História e Geografia do Brasil". (FANFULLA, 1906, p. 822, tradução nossa).

Vê-se que essa Comissão estava informada a respeito da legislação brasileira, porque a lei que obrigava as escolas estrangeiras ao ensino da língua portuguesa, História do Brasil e Geografia era do ano de 1896. O inspetor escolar Miguel Carneiro Junior escreveu em seu relatório a esse respeito:

A Lei n. 489 de 29 de Dezembro de 1896 torna obrigatorio o ensino da lingua nacional, bem como o da geographia e da historia do Brazil, nas escolas estrangeiras. Como porém, essa lei não esta regulamentada, o inspetor escolar só póde averiguar si nessas escolas é ou não feito tal ensino. (SÃO PAULO, 1907, p. 396).

A Comissão, nesse momento, considerava de grande valia a aprendizagem da língua portuguesa, em função da expansão das relações comerciais. Apesar de as escolas italianas na cidade paulistana seguirem o programa de ensino do 
governo da Itália, que primava pelo nacionalismo. Mas, em contraponto, algumas dessas escolas mantinham o ensino da língua portuguesa, além de oferecerem o curso primário e o curso noturno para adultos; contavam com aulas de exercícios ginásticos, cursos preparatórios para o ingresso no superior, cursos de trabalhos manuais, de língua francesa, entre outros. E, segundo Salvetti (1995), no ano de 1904, o governo brasileiro passou a impor normas e programas escolares às escolas italianas. Era uma forma de manter essas escolas sob supervisão do governo estadual paulista.

Conforme Moacyr (1942) nos dados que constavam do relatório do Inspetor Geral do Ensino Mario Bulcão, no ano de 1900, as escolas particulares de estrangeiros na capital em geral não ensinavam a língua portuguesa.

[...] na Capital, em sua maioria, são escolas dirigidas por estrangeiros nas quais não se ensina a língua vernacula embora os respectivos professores digam que o fasem. O numero de alunos classificados como estrangeiros são creanças nascidas no país. Dos 14.367 alunos das escolas privadas. Destes são nacionais 11.242 e estrangeiros 3.125. É claro que a maior parte dos alunos os classificados como estrangeiros são creanças nascidas no Brasil, filhos de pais estrangeiros, para cujo ensino devemos lançar as nossas vistas. (MOACYR, 1942, p. 115).

Verificou-se na análise dos documentos que nem todas as escolas subsidiadas italianas incluíam o curso de língua portuguesa no programa. Mas, estranhamente, indicavam que estavam em concordância com o programa de ensino paulista. Uma hipótese para essas escolas manterem o curso de língua portuguesa era a existência da necessidade de se alfabetizarem os adultos na língua do país, para que houvesse maior clareza nas relações comerciais. Não necessariamente pelo motivo de que os diretores dessas escolas pudessem sofrer alguma retaliação do governo paulista, caso fosse inexistente o ensino da língua portuguesa.

Nos debates ocorridos no Congresso delle Società ed altre Istituzioni Italiane, surgiu em um dos tópicos a mesma questão sobre o aprendizado. Os imigrantes deveriam "aprender a falar e escrever a língua nacional", porque esse não era "[...] somente dever do hóspede, mas necessidade imprescindível para todos os italianos que aqui residiam”. (FANFULLA, 1906, p. 823, tradução nossa). Não se pode afirmar que as escolas subsidiadas ensinavam seus alunos no idioma instituído no Reino Italiano, talvez ensinassem com o uso dos idiomas regionais. Presume-se que esses idiomas das regiões estavam sendo suprimidos 
a cada dia, porque o subsídio do governo italiano a essas escolas se vinculava à necessidade de se ensinar a língua italiana.

Sendo assim, o ensino e a consequente aprendizagem da língua portuguesa decorriam de questões básicas de convívio, da necessidade do diálogo para a aquisição e comércio de bens e produtos. Mas, no relatório do Inspetor Geral do Ensino João Lourenço Rodrigues em 1907, o entendimento era sobre o aprendizado da língua portuguesa como forma de tornar as crianças cidadãs brasileiras e, ao mesmo tempo, para os pais dessas crianças esse aprendizado seria útil para as negociações e o comércio.

Resta saber si taes estabelecimentos, em que o portuguez não é língua official, podem offerecer ao Estado reaes vantagens como auxiliares do Governo na ministração do ensino preliminar.

Não só a difficuldade de conseguir logar em nossas escolas publicas, em vista da desproporção entre o numero de candidatos à matricula e a lotação desses estabelecimentos, como tambem o desejo de que seus filhos aprendam a língua patria, faz com que os estrangeiros domiciliados em nosso paiz, principalmente os italianos, procurem escolas particulares. Ora, é natural que a colonia italiana procure de preferencia essas escolas onde as crianças, aprendendo a lingua, a geografia e a historia da Italia, aprendem, por isso mesmo, a amar a Italia.

É natural também que essas escolas, mais ou menos protegidas pelo governo italiano - ao passo que o governo do Estado em nada as auxilia - se vão lentamente afastando de nós e, cada vez mais, por assim dizer, italianisando o ensino. (SÃO PAULO, 1907, p. 43).

Sabe-se que as ações do governo italiano visavam à perpetuação do sentimento de amor à pátria, justificando-se, deste modo, a distribuição de livros de leitura e o envio de subsídios em dinheiro. Salvetti (1995) citou a Ata do Primeiro Congresso dos Italianos no exterior ocorrido em Roma no ano de 1910, que reforçava a manutenção dos subsídios. As discussões desse congresso abordaram a necessidade de:

[...] a federação da sociedade mantenedora das escolas e ensino, Deputados e Conselhos que coordenam e regulam as várias instituições e Conselhos escolares existentes em determinadas localidades; proponham-se a distribuir amplamente livros de texto para os alunos; instituir escolas e sociedades, bibliotecas circulantes de acordo com a Dante Alighieri; disciplinar a concessão de subsídios em dinheiro, proporcionalmente 
ao número de alunos e aos recursos econômicos das várias escolas, declarando-os renováveis a cada ano, de modo a servir da incentivo aos bons procedimentos. (SALVETTI, 1995, p. 117, tradução nossa).

Percebeu-se que a discussão sobre as escolas no exterior continuava a tratar da criação de escolas, de bibliotecas e da necessidade da distribuição de livros para o ensino. Nas escolas da capital paulista, normalmente, o professor regia a escola masculina e sua esposa ou filhas regiam a escola feminina. Os professores dessas escolas - como descrevem as fontes: Fanfulla (1906), Annuario do Ensino do Estado de São Paulo (1908) e Annuario delle scuole italiane all'estero governative e sussidiate (1908) - eram de origem peninsular, ou eram filhos de peninsulares que tinham fluência no idioma da região de origem de sua família.

Nesse sentido, a imposição do ensino da língua portuguesa era a cada dia mais necessária. Apesar de todos os peninsulares moradores na cidade de São Paulo serem reconhecidos como italianos pelas outras etnias, eles viviam em bairros em que se identificavam regionalmente, dando margem para o uso de outros idiomas no cotidiano.

Simultaneamente, a escola pública dos anos iniciais, existente na cidade de São Paulo, era coroada pela criação dos grupos escolares. O ensino primário, após a proclamação da república, como foi apresentado por Souza (2009), revelava o sentido da educação popular. A autora enfatizou ainda que educar supunha um compromisso com a formação integral da criança, que ia muito além da simples transmissão de informações fornecidas pela instrução, implicava, essencialmente, a formação do caráter mediante a aprendizagem da disciplina social, das virtudes morais e dos valores cívico-patrióticos necessários à formação do espírito da nacionalidade.

Logo, as escolas elementares, públicas e as privadas subsidiadas visavam objetivos similares, quanto ao aprendizado da língua dos respectivos países e ao ideal de formação do cidadão.

\section{Considerações finais}

Nesse momento, vivia-se um embate, porque as escolas públicas paulistanas, principalmente os grupos escolares e as escolas subsidiadas italianas buscavam o mesmo fim, ambas pretendiam a alfabetização de seus alunos, em suas respectivas línguas nacionais, para assim formarem os cidadãos. 
O governo do Estado tomou providências para ampliar o número de vagas nos grupos escolares na capital. No ano de 1910, existiam ao todo 24 estabelecimentos em funcionamento na cidade, sendo destes sete novos, conforme o Annuario do Ensino do Estado de São Paulo do ano de 1910. O bairro do Brás era o único que contava com três grupos, essa iniciativa do governo era justificada pelo grande número de crianças em idade escolar nessas cercanias e pelo alto número de famílias de operários estrangeiros que lá viviam. Mas, ainda assim, as vagas existentes nos grupos e nas escolas isoladas não eram suficientes para suprir a demanda. O relatório do Diretor Geral da Instrução Publica, João Chrysostomo Bueno dos Reis Junior, contido no Annuario do Ensino do Estado de São Paulo analisou a situação:

Não esqueçam os srs. Representantes do município de que só no Braz - a estatística ahi está para o affirmar com a clareza de seus algarismos - muito mais de 2 mil crianças, nascidas aqui, freqüentam por falta de logar nos estabelecimentos do Estado, escolas que recebem subvenção do extrangeiro, escolas onde o nome do Brazil, da sua terra, é vagamente ouvido de quando em vez. (SÃO PAULO, 1910, p. 27).

No ano de 1910 o número de escolas isoladas foi reduzido, muitas foram anexadas e tornaram-se grupos escolares, reorganizando o ensino e ampliando a oferta de vagas. Existiam, neste ano, 101 escolas isoladas na capital, a pretensão do governo em transformá-las em escolas reunidas e, posteriormente, em grupos escolares estava sendo colocada em prática. Mesmo que, algumas delas, tenham alterado sua categoria, sem chegarem a ser reunidas, conforme dados do Annuario do Ensino do Estado de São Paulo de 1910. Além disso, as três escolas reunidas da capital foram elevadas à categoria de grupos escolares no ano letivo de 1909.

Os esforços do governo paulista em ampliar o número de vagas nas escolas elementares foram os mais diversificados. Na mesma época, alguns estabelecimentos de ensino públicos passaram a "desdobrar os horários", atendendo alunos durante os períodos matutino e vespertino, de modo a oferecerem mais vagas. Simultaneamente, as escolas subsidiadas de peninsulares foram reduzindo drasticamente suas vagas, muitas encerraram suas atividades, principalmente durante os anos da Grande Guerra. Desta forma, as escolas públicas paulistanas acabaram por receber, paulatinamente, os alunos que frequentavam as antigas escolas subsidiadas, onde o ensino da língua portuguesa predominava. 


\section{REFERÊNCIAS}

BIONDI, L. Imigração italiana e movimento operário em São Paulo: um balanço historiográfico. In: CARNEIRO, M. L. T.; CROCI, F.; FRANZINA, E. (Orgs.). História do trabalho e História da imigração: trabalhadores italianos e sindicatos no Brasil (séculos XIX e XX). São Paulo: EDUSP: FAPESP, 2010. p. 23-48.

CATANI, D. B.; LIMA, A. L. G. Vigilância e controle: os Anuários do Ensino do Estado de São Paulo e a História do trabalho docente no Brasil. (1907-1937). In: CATANI, D. B.; BASTOS, M. H. C. (Orgs.). Educação em revista: a imprensa periódica e a História da Educação. São Paulo: Escrituras, 2002. p. 155-172.

CENNI, F. Italianos no Brasil: andiamo in'Merica. 3. ed. São Paulo: EDUSP, 2003.

FANFULLA. Il Brasile e gli italiani. Firenze: R. Bemporad \& figlio, 1906.

ITÁLIA. Annuario delle scuole italiane all'estero governative e sussidiate. Roma: Ministero degli Affari Esteri. Ispettorato Generale delle Scuole all'estero, 1908.

MIMESSE, E. A educação e os imigrantes italianos: da escola de primeiras letras ao grupo escolar. 2. ed. São Paulo: Iglu, 2010.

MOACYR, P. A instrução Pública no Estado de São Paulo: primeira década republicana 1890-1900. São Paulo: Companhia Editora Nacional, 1942.

PEREIRA, R. M. Washington Luís na administração de São Paulo (1914-1919). São Paulo: Editora da UNESP, 2010.

SALVETTI, P. Immagine nazionale ed emigrazione nella Società "Dante Alighieri". Roma: Bonacci, 1995.

SALVETTI, P. Le scuole italiane all' estero. In: BEVILACQUA, P.; DE CLEMENTI, A.; FRANZINA, E. Storia dell' emigrazione italiana: arrivi. Roma: Donzelli, 2002. v. 2. p. 535-549.

SALVETTI, P. Governo Italiano, Diplomacia e Escolas Italianas no Exterior. In: LUCHESE, T. A. História da escola dos imigrantes italianos em terras brasileiras. Caxias do Sul, RS: EDUCS, 2014. p. 57-77.

SÃO PAULO. Annuario do Ensino do Estado de São Paulo: publicação organisada pela Inspectoria Geral do Ensino por ordem do Governo do Estado. São Paulo: Typ. A. Siqueira \& C., 1907-1910.

SOUZA, R. F. de. Templos de civilização: a implantação da escola primária graduada no estado de São Paulo (1890-1910). São Paulo: Editora da UNESP, 1998.

SOUZA, R. F. de. Alicerces da Pátria: escola primária e cultura escolar no Estado de São Paulo (1890-1976). Campinas, SP: Mercado de Letras, 2009. 
PRADO, E. M. O convivio concomitante e frugal das escolas elementares públicas e privadas...

TRENTO, A. Brasile. In: BEVILACQUA, P.; DE CLEMENTI, A.; FRANZINA, E. Storia dell' emigrazione italiana: arrivi. Roma: Donzelli, 2002. v. 2. p. 3-23.

Texto recebido em 21 de abril de 2015. Texto aprovado em 30 de outubro de 2015. 